\title{
The Patient Care Ownership Scale: Development of an Instrument to Measure Patient Care Ownership Among Internal Medicine Trainees
}

\author{
Mia Djulbegovic, $M D^{1,2}$, Jason W. Beckstead, $P h D^{3}$, and Liana Fraenkel, $M D^{2,4}$
}

${ }^{1}$ National Clinician Scholars Program, Yale University School of Medicine, New Haven, CT, USA; ${ }^{2}$, Veterans Affairs Connecticut Healthcare System, West Haven, CT, USA; ${ }^{3}$ College of Public Health, University of South Florida, Tampa, FL, USA; ${ }^{4}$ Section of Rheumatology, Yale University School of Medicine, New Haven, CT, USA.

\begin{abstract}
BACKGROUND: Patient care ownership is essential to delivering high-quality medical care but appears to be eroding among trainees. The lack of an objective measure has limited the study of ownership in physicians.

OBJECTIVE: To develop an instrument to measure psychological ownership of patient care.

DESIGN: Cross-sectional study.

PARTICIPANTS: Internal medicine trainees in a large, academic hospital completing an inpatient rotation.

MAIN MEASURES: Our scale prototype adapted an existing ownership scale (developed in the non-medical setting) based on themes identified in qualitative studies of patient care ownership. We conducted cognitive interviews to determine face validity of the scale items. Our finalized scale measures ownership's key constructs: advocacy, responsibility, accountability, follow-through, knowledge, communication, initiative, continuity of care, autonomy, and perceived ownership. We distributed an online, anonymous, 46-question survey to 219 residents; 192 residents completed the survey; and 166 responses were included in the analysis. We calculated Cronbach's $\alpha$ to determine the scale's internal consistency. Exploratory factor analysis was used to explore possible subscales. We examined construct validity using bivariate and correlational analysis.
\end{abstract}

KEY RESULTS: The 15-item ownership scale demonstrated good internal consistency (Cronbach's $\alpha=0.89$ ). We identified three possible subscales corresponding to assertiveness, being the "go-to" person, and diligence. Training level and prior intensive care unit experience significantly predicted ownership $(p<0.01)$. There was no significant relationship between ownership and age, gender, inpatient service type, call schedule, patient turnover, or supervisory experience of the attending physician. We found a significant negative correlation between ownership and perceived degree of burnout $(r=-0.33)$,

Prior Presentations This work was presented as an oral abstract at the Society of General Internal Medicine annual meeting in April of 2018 in Denver, CO.

Electronic supplementary material The online version of this article (https://doi.org/10.1007/s11606-019-05066-8) contains supplementary material, which is available to authorized users.

Received August 4, 2018

Revised February 7, 2019

Accepted April 10, 2019

Published online June 3, 2019 depression $(r=-0.24)$, detachment $(r=-0.35)$, and frustration $(r=-0.31)$ and a significant positive association between ownership and fulfillment $(r=0.37)$ and happiness $(r=0.36)$.

CONCLUSION: We developed an instrument to quantify patient care ownership in residents. Our scale demonstrates good internal consistency and preliminary evidence of validity. With further validation, we expect this to be a valuable tool to evaluate interventions aimed at improving ownership.

\begin{abstract}
KEY WORDS: medical education; medical decision-making; behavioral science.

J Gen Intern Med 34(8):1530-7

DOI: $10.1007 / \mathrm{s} 11606-019-05066-8$

(c) Society of General Internal Medicine (This is a U.S. government work and not under copyright protection in the U.S.; foreign copyright protection may apply) 2019
\end{abstract}

\section{INTRODUCTION}

Ownership (also termed decision ownership and psychological ownership) is a complex concept that is essential to delivering high-quality medical care. ${ }^{1}$ Ownership of patient care is defined as a cognitive-affective state that utilizes both analytical and emotional processes to arrive at a decision. ${ }^{1,2}$ During high ownership states, the decision-maker reflects on their knowledge, beliefs, experience, and skills (cognitive component) as well as feelings of self-efficacy and competence (emotional component). ${ }^{1}$ The possessive nature of decision ownership — where the clinician becomes personally invested in the decisions made for their patients - is what differentiates it from similar concepts such as responsibility and commitment. ${ }^{1}$ Decision ownership influences human motivation, attitudes, and behavior, suggesting that ownership may also affect physician decision-making and care utilization. ${ }^{1-6}$ Fostering ownership among medical trainees is expected to increase accountability and responsibility and improve clinical skills, patient care, and patient outcomes. ${ }^{1}$ Yet, ownership appears to be gradually eroding by trainees since the implementation of the 2011 Accreditation Council for Graduate Medical Education work hour regulations and the resulting 
increase in shiftwork. ${ }^{1,}{ }^{7-11}$ How this decline in ownership relates to clinical skills development, quality of patient care, and long-term outcomes is unknown partially due to the lack of an instrument that measures patient care ownership.

Several instruments that measure decision ownership have been validated in the field of organizational psychology. ${ }^{6,12-14}$ The most recent instrument, developed by Avey et al., demonstrates acceptable to excellent psychometric reliability. ${ }^{6,15}$,

${ }^{16}$ The scale consists of five key constructs that measure the multi-dimensional concept of ownership: self-efficacy, accountability, sense of belongingness, self-identity, and territoriality. ${ }^{6}$ Ownership in the medical literature has been limited to qualitative studies ${ }^{17,18}$ and single-item questionnaires asking trainees and attending physicians whether decision ownership has worsened with stricter work hours and increased hand-offs. ${ }^{7-11}$ Two qualitative descriptive studies that each sought to define ownership of patient care as it pertains to physicians identified similar constructs. ${ }^{17,18}$ Analysis of narrative responses from attending and resident physicians in a 2013 study conducted by McLaren et al. identified advocacy, autonomy, commitment, communication, follow-through, knowledge, and teamwork ${ }^{17}$ as core elements of ownership. The more recent study, led by Cowley et al. in 2017, identified themes of advocacy, communication, care coordination, decision-making, follow-through, knowledge, leadership, attitudes of going "above and beyond" and "the buck stops here," responsibility, serving as primary provider, demonstrating initiative, and providing the best care as central to ownership of patient care.

An instrument that measures physicians' ownership of patient care is essential to further investigation of the unique influence of ownership on physician decision-making and healthcare outcomes. Such an instrument could potentially guide medical educators who aim to foster patient care ownership in trainees. Accordingly, we developed a scale intended to reliably measure and quantify ownership of patient care based on previous research. ${ }^{12,17,18}$

\section{METHODS}

\section{Scale Development}

We developed items deductively based on the earlier work by Avey et al. ${ }^{12}$ Specifically, we adapted this scale to the constructs and themes identified in the studies by McLaren et al. and Cowley et al. ${ }^{17,}{ }^{18}$ We constructed items with the goal of minimizing social desirability bias and the ceiling effect. ${ }^{16}$ After developing a prototypic, 20-question ownership scale, we conducted cognitive interviews to assess the face validity of the scale items. We used purposeful sampling ${ }^{19}$ to select participants who were either knowledgeable about or expressed an interest in medical education. Each interview was conducted by the primary investigator. Each scale item was reviewed using the think aloud approach with concurrent, scripted verbal probing. Interviewees were asked to identify (from a list of options) which construct the scale item intended to measure (e.g., autonomy), whether respondents will answer honestly (or if the item was subject to social desirability bias), whether the item was subject to the ceiling effect, and if they had any suggestions on revising the item. Trainees who participated in the cognitive interview were not invited to complete the survey. Scale items were revised using an iterative process. Cognitive interviewing concluded when responses were saturated (i.e., when no further changes were made to the scale after the interview). Each version of the scale, including the original 20-question prototype, and the changes made during the cognitive interviewing process are detailed in Appendix B (online).

\section{Data Collection}

Based on the results of the cognitive interviews, we developed a survey which included a 16-item ownership scale to measure its key constructs: advocacy, responsibility, accountability, followthrough, knowledge, communication, initiative, continuity of care, autonomy, and perceived ownership. Items were rated on 7-point Likert-type scales ${ }^{20}$ ranging from $1=$ strongly disagree to $7=$ strongly agree. The survey also included questions on demographic information, work environment, patient characteristics, and perceived degree of introversion or extroversion. We also included items that measure perceived degree of stress, depression, exhaustion, burnout, emotional detachment, frustration, fulfillment, and happiness (rated on 6-point scales, ranging from $1=$ never to $6=$ always). The final ownership scale and the corresponding constructs that each item measures are in Table 1. The complete survey is included in Appendix A (online).

The online survey was distributed to internal medicine residents training in the Yale New Haven-Hospital traditional, primary care and combined internal medicine-pediatrics program between April 2017 and June 2017. At the conclusion of an inpatient rotation, trainees were invited to take the online survey (using Qualtrics survey software) and were instructed to answer the survey questions according to their experience on that rotation. Trainees who did not complete the survey were automatically reminded on a daily basis for 2 weeks. To avoid duplicate responses, trainees who declined or completed the survey were not re-invited to participate at the conclusion of subsequent inpatient rotations. Prior to opening the survey, respondents were provided with a detailed information sheet that explained the nature of the survey and the intended use of their anonymous responses (Appendix A [online]). We enabled force response for all survey questions to prevent any missing data. Participants were enrolled into a lottery to win one of three 50-dollar gift cards. The study was deemed exempt from Internal Review Board review by the Yale University Human Investigation Committee.

\section{Statistical Analysis}

For each respondent, we calculated a total ownership score by taking the summative score of all items and dividing that by the number of items. We used descriptive statistics to determine mean (standard deviation) ownership in our study population. We calculated Cronbach's $\alpha$ to determine the internal 
Table 1 Ownership Scale (16-item)

$\overline{\overline{\text { Dimension }}}$

Responsibility, accountability, and follow-through

\section{Knowledge \\ Communication}

Initiative

Continuity of care

Autonomy

Perceived ownership

Item

1. I was vocal and assertive about my patients' best treatment/care.

2. I felt comfortable telling the attending what I felt was the right thing to do for my patients, rather than just letting them decide.

3 . I challenged the team as needed if I felt it was in my patients' best interest, no matter how much push back I got.

1. I frequently deferred to other providers for many aspects of my patients' care. (reverse ${ }^{*}$ )

2. I personally made sure to go back and check that all orders were actually carried out.

3. When carrying out my patient's management plan, I took extra care to make sure that things did not fall through the cracks.

4. I felt responsible for my patients' care, even after my shift ended.

1. I was the "go-to" person for knowledge about my patients.

1. I made sure that the nursing staff was updated with the day's plan. 2 . I felt that my sign -outs could have been more effective (reverse) ${ }^{\dagger}$

1. I was proactive in checking up on my patients, rather than being called with questions or concerns.

1. I ensured good continuity of care even when I was absent from the service.

1. I was given the opportunity to make decisions independently about my patients' care.

2. I felt that my attending(s) micromanaged me (reverse)

3. I felt comfortable making decisions independently about my patients' care.

1. I felt a strong sense of ownership of my patients' care.

The final, 16-item ownership scale distributed to medicine trainees. This scale measures ownership's key constructs: advocacy, responsibility, accountability, follow-through, knowledge, communication, initiative, continuity of care, autonomy, and perceived ownership

* Reverse refers items that measure the reverse dimension. Responses were re-coded, such that answering "7" (strongly agree) on the original survey was re-coded to "I" (strongly disagree) in the data analysis

${ }^{t}$ This item was eventually removed from the scale because doing so led to an increase of Cronbach's $\alpha$

consistency of the scale. We performed bivariate and correlational analysis to examine construct validity and to determine correlates of ownership. We evaluated the relationship between ownership and perceived degree of stress, depression, exhaustion, burnout, detachment, frustration, fulfillment, and happiness with correlational analysis. We performed exploratory factor analysis to identify possible subscales. We analyzed the data using principal axis factoring and varimax rotation in SPSS's FACTOR procedure. Prior to extraction, the correlation matrix was assessed using Kaiser-Meyer-Olkin (KMO) measure and Bartlett's test of sphericity. We performed pairwise correlations to determine if there was any significant relationship between training level and any of the resulting factors. We used SPSS and Stata statistical packages for all analyses.

\section{RESULTS}

\section{Cognitive Interviewing}

The first version of the ownership scale included items that measured all the constructs identified by Avey et al., ${ }^{6}$ McLaren et al. ${ }^{17}$, and Cowley et al. ${ }^{18}$ We made several modifications to the scale based on the cognitive interviews, which concluded after six interviews (four internal medicine residents and two attending physicians). Items were removed if there was no face validity or if $\geq 2$ interviewees felt that the question was at high risk of social desirability bias or the ceiling effect.

Prior research in organizational psychology suggests that territoriality is an essential aspect of decision ownership. , $^{\text {, }}$ ${ }^{21}$ However, the items intended to measure territoriality had low face validity as most interviewees felt that territoriality is not relevant to patient care ownership. Therefore, items measuring territoriality were removed. Items measuring the communication dimension required the most revision. According to the interviewees, each iteration of the items measuring communication did not adequately capture the variable quality in hand-offs or transitions of care. Interviewees felt that the quality in hand-offs was also influenced by external factors independent of ownership, such as acuity of care, medical complexity, and cultural norms. Based on interviewees' input, our final scale included items that measured the trainee's subjective quality of their communication with the nursing staff and their hand-off at change of shift (Table 1). The latter of these two items was eventually removed (see the "Internal Consistency of the Scale" section). Similarly, items that measure time spent face-to-face with patients were removed because rounding inefficiency, patient turnover, administrative load, and clinical acuity all affect time spent with patients. Additionally, while commitment and self-efficacy are also thought to be inherent to ownership of patient care, items measuring these concepts were deleted because interviewees felt that they would be subject to the social desirability bias and the ceiling effect.

\section{Study Participants}

Of the 222 trainees in the Yale New Haven-Hospital traditional, primary care and combined internal medicine-pediatrics program, 219 were invited to participate, and 192 completed the survey. We excluded responses from 26 trainees either because of the time spent completing the survey $(<1 \mathrm{~min}$ or $\geq 24 \mathrm{~h}$ ) or because of zero variance among responses (Fig. 1). Responses from 166 trainees were included in the analysis.

There were no significant differences between the participants who were included in the analysis $(n=166)$ and those who were excluded $(n=26)$ with respect to gender, prior experience in the intensive care unit (ICU), training level, training program, service type, call schedule, attending physician characteristics, patient turnover, or acuity of care. There was a statistically significant difference in age. Those who 


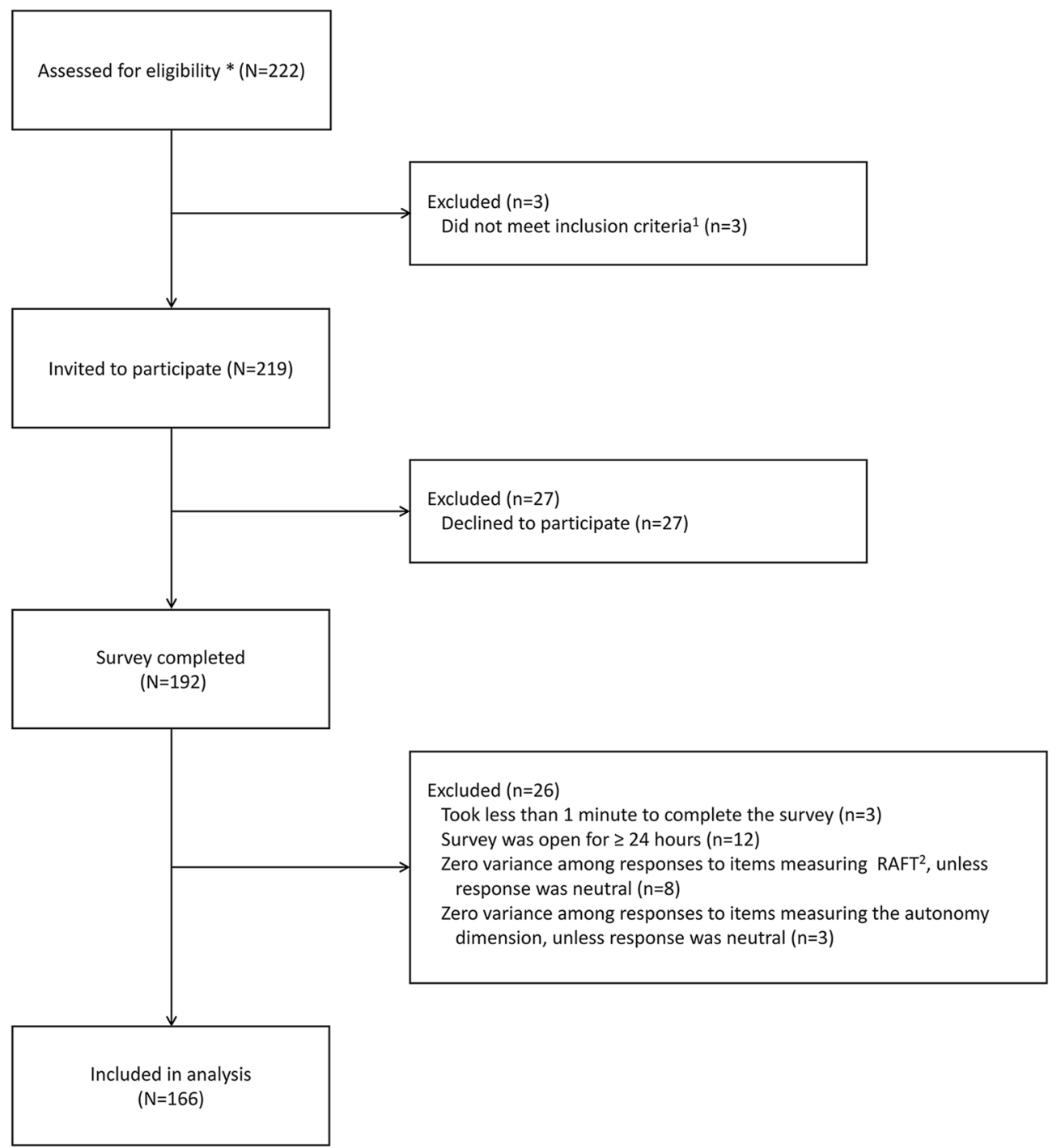

Figure 1 CONSORT diagram. Flow diagram identifying the participants whose survey responses were included in the analysis. Asterisk symbol indicates that trainees who participated in the cognitive interviews were not considered eligible and are not represented. Superscripted digit 1 indicates trainees who were not on an inpatient service at during study enrollment. Superscripted digit 2 indicates the rationale behind dropping observations related to zero response variance, which was based on an item set with three or more items that includes at least one reverse item. Since reverse items should generate the opposite response of the remaining items measuring the same dimension (e.g., those who selected "strongly agree" for items that measure autonomy, should not have selected the same for the reverse item, assuming that the item truly measures the dimension that it is intended to capture), those observations with zero variance were considered untruthful. Responses with a zero variance were, however, included in the analysis if the response to the reverse item (that required recoding) was "neither agree nor disagree." RAFT, responsibility, accountability, and follow-through dimension.

were included in the analysis were, on average, 1.4 years younger compared with those who were excluded. The proportion of participants included in the analysis by training level was representative of the residency program. The median time it took to complete the survey was $4.7 \mathrm{~min}$ (ranging from $2.4 \mathrm{~min}$ to $22.8 \mathrm{~h}$ ). The baseline characteristics of the study participants are detailed in Table 2.

\section{Internal Consistency of the Scale}

Cronbach's $\alpha$ for the 16-item ownership scale was 0.88 . When Cronbach's $\alpha$ was re-calculated for each item removed, we found that removal of the second item measuring the communication dimension (Table 1) led to an increase in Cronbach's $\alpha$ to 0.89 . When we removed this item, the mean inter-item correlation increased from 0.32 (on the 16-item scale) to 0.34 (on the 15 -item scale). The correlation between the deleted item and the 15-item scale that excludes that item was 0.20 . Removing other items decreased Cronbach's $\alpha$, so the remaining analysis was done according to the 15 -item scale (i.e., with only one item measuring the communication dimension, instead of the original two). The mean responses to the 15-item ownership scale were close to normally distributed (Shapiro-Wilk test of normality, $p=0.07)$. The mean $(\mathrm{SD})$ on the 15-item ownership scale was $5.57(0.74)$, and the median was 5.6 (range $=3.1$ to 7 ). 
Table 2 Baseline Characteristics of Study Participants $(N=166)$

\begin{tabular}{|c|c|}
\hline Variable & No. $(\%$ of $N)$ \\
\hline \multicolumn{2}{|l|}{ Age } \\
\hline Median (range), years & $29(23-43)$ \\
\hline \multicolumn{2}{|l|}{ Gender } \\
\hline Female & $80(48)$ \\
\hline Male & $86(52)$ \\
\hline \multicolumn{2}{|l|}{ Level of training } \\
\hline PGY-1 & $81(49)$ \\
\hline PGY-2 & $45(27)$ \\
\hline PGY-3 & $40(24)$ \\
\hline \multicolumn{2}{|l|}{ Prior ICU experience } \\
\hline $0-1$ months & $51(31)$ \\
\hline $2-3$ months & $73(44)$ \\
\hline$\geq 4$ months & $42(25)$ \\
\hline \multicolumn{2}{|l|}{ Training program* } \\
\hline Internal medicine, traditional program & $102(62)$ \\
\hline Internal medicine, primary care program & $32(19)$ \\
\hline Internal medicine-pediatrics & $7(4)$ \\
\hline Internal medicine, preliminary track & $25(15)$ \\
\hline Anesthesiology & $8(5)$ \\
\hline Dermatology & $3(2)$ \\
\hline Neurology & $8(5)$ \\
\hline Psychiatry & $5(3)$ \\
\hline Radiation oncology & $1(1)$ \\
\hline \multicolumn{2}{|l|}{ Duration on service } \\
\hline 2 weeks & $71(43)$ \\
\hline 4 weeks & $95(57)$ \\
\hline \multicolumn{2}{|l|}{ Type of inpatient service } \\
\hline General medicine ward & $84(51)$ \\
\hline Subspecialty ward & $31(19)$ \\
\hline SDU & $8(5)$ \\
\hline & $41(25)$ \\
\hline \multicolumn{2}{|l|}{ Call $^{\dagger}$ schedule } \\
\hline 28-h call every fourth night & 32 (19) \\
\hline Day/night float system & $134(81)$ \\
\hline Both days and nights & $28(17)$ \\
\hline Days & $87(52)$ \\
\hline Nights & $18(11)$ \\
\hline
\end{tabular}

Baseline characteristics of the participants included in the study ( $N=$ 166)

$P G Y$ post-graduate year, SDU step-down unit, ICU intensive care unit * The traditional residency program, primary care training program, and combined internal-medicine pediatrics training program all share the common goal of training residents in internal medicine. The key differences between the traditional and primary care medicine programs are time spent in inpatient vs. ambulatory medicine during residency training, and the proportion of residents who pursue subspecialty training after graduation (typically a higher rate of graduates from the traditional medicine training program). The combined internal medicine-pediatrics training program also trains residents in pediatric medicine. The preliminary training program encompasses 1 year of mandatory internal medicine training prior to initiation of training in another specialty which the resident will ultimately pursue board certification in (e.g., dermatology) ${ }^{\dagger}$ Call refers to a shift ranging between 24 and $28 \mathrm{~h}$ that is spent entirely in the hospital. Residents who were not taking call every fourth day were on service with a day/night float. Some day/night float systems required taking some call to relieve the night resident (on average, this would occur about once weekly). ${ }^{t}$ Residents who were on a service with a day/night float system for four weeks may have spent 2 weeks on days and the other 2 weeks on nights.

\section{Bivariate and Correlational Analysis}

Ownership significantly increased with training level. The mean (SD) ownership was 5.37 (0.82), 5.59 (0.54), and 5.96 (0.61) among participants who were in their first, second, and third post-graduate years $(p<0.01)$, respectively. The number of months previously spent in the ICU during residency training was also a significant predictor of ownership. The mean
(SD) ownership was $5.31(0.85), 5.59(0.68)$, or $5.85(0.58)$ among participants with $0-1$ months, $2-3$ months, or $\geq$ 4 months of previous experience in the ICU $(p<0.01)$, respectively. In a multivariable regression model, the effect of ICU experience was not statistically significant.

There was no statistically significant difference in ownership between males and females, those who took 28-h call every fourth day vs. day/night service, or between those who were on service for 2 vs. 4 weeks. Ownership also did not vary significantly according to age, service type, training program, perceived supervisory experience of the attending physician (in years), admission rate, average length of stay of the patients, nor acuity of care.

We found a significant negative correlation between ownership and perceived degree of depression $(r=-0.27, p=$ $0.02)$, burnout $(r=-0.32, p<0.01)$, detachment $(r=-0.35$, $p<0.01)$, and frustration $(r=-0.31, p<0.01)$ and a significant positive association between ownership and fulfillment $(r=0.37, p<0.01)$ and happiness $(r=0.36, p<0.01)$. We present a graphical depiction of the relationship between ownership and burnout, depression, happiness, and fulfillment in Figure 3. There was no statistically significant relationship between ownership and stress nor exhaustion.

\section{Factor Analysis}

Exploratory factor analysis identified three factors (using Eigenvalue >1). Both the KMO measure and Bartlett's test of sphericity indicated that the data were appropriate for factor analysis $(\mathrm{KMO}=0.878$, Bartlett's test $=1015.584, \mathrm{df}=105$, $p<0.001$ ). The rotated matrix is reported in Table 3. Using factor loading of $\geq 0.5$, we identified three possible subscales corresponding to assertiveness, being the "go-to" person, and diligence. Only factor 1 (assertiveness) correlated with training level $(r=0.28, p<0.01)$.

Table 3 Exploratory Factor Analysis of the 15-Item Ownership Scale

\begin{tabular}{llll}
\hline \hline Item & Factor $\mathbf{1}$ & Factor 2 & Factor 3 \\
\hline Advocacy Q1 & 0.514 & 0.491 & 0.167 \\
Advocacy Q2 & 0.583 & 0.477 & 0.085 \\
Advocacy Q3 & 0.792 & 0.167 & 0.180 \\
RAFT Q1R & 0.413 & 0.330 & 0.295 \\
RAFT Q2 & 0.086 & 0.073 & 0.686 \\
RAFT Q3 & 0.241 & 0.042 & 0.780 \\
RAFT Q4 & 0.351 & 0.205 & 0.333 \\
Knowledge & 0.231 & 0.637 & 0.276 \\
Communication Q1 & 0.114 & 0.087 & 0.513 \\
Initiative & 0.135 & 0.476 & 0.455 \\
Continuity of care & 0.133 & 0.226 & 0.371 \\
Autonomy Q1 & 0.430 & 0.576 & 0.154 \\
Autonomy Q2R & 0.167 & 0.585 & 0.004 \\
Autonomy Q3 & 0.788 & 0.208 & 0.222 \\
Perceived ownership & 0.544 & 0.436 & 0.299 \\
\hline
\end{tabular}

Extraction method: principal axis factoring. Rotation method: varimax with Kaiser Normalization

$Q$ question, $R$ recoded, $R A F T$ responsibility, accountability, and followthrough dimension 


\section{DISCUSSION}

Ownership of patient care is a complex concept that is inherently well known to most clinicians. While patient care ownership is thought to be important to clinical skill development and delivering high-quality care, it appears to be declining among trainees. In order to improve patient care ownership, we need to be able to measure it first. To our knowledge, this is the first report of an objective measure of patient care ownership that captures its multiple constructs. Our 15-item ownership scale demonstrates good internal consistency and construct validity. Both the qualitative (cognitive interviewing) and quantitative (survey data) findings from our study contribute to a working definition of ownership (Fig. 2).

One of our key findings is the association between training level and ownership. Though we cannot prove causality, we speculate that training level is a surrogate for knowledge and clinical experience. Our scale does include one item measuring the knowledge dimension but was restricted to patientspecific information and did not tap into a more general fund of knowledge nor clinical acumen. We did not find any other significant relationships between the other independent variables (work schedule, characteristics, and turnover of both patients and supervising physicians) and ownership. This may be because our sample size was not large enough to detect true differences in ownership according to these variables. Or, maybe our survey did not capture the real issues related to work environment that likely negatively influence ownership, such as degree of clerical burden (e.g., number of hours spent documenting in the electronic record). It is more likely, however, that these factors are associated with the burden of nonmeaningful work, and that their relationship to ownership is indirect. Our findings on the relationship between burnout and ownership support this possibility (Fig. 3).

The inverse relationship between ownership and perceived degree of burnout and positive relationships between ownership and a sense of happiness and fulfillment are consistent with those of a Mayo Clinic study, ${ }^{22}$ where physicians who experienced more burnout were less likely to identify with medicine as a calling. Although we do not know if decreased ownership leads to more burnout or vice versa, causality may be less important since interventions can target both. External factors such as excessive workload, loss of control over workload, clerical burden, inefficient workflow, and work-life balance all contribute to physician burnout ${ }^{23,24}$ and probably also negatively influence ownership of patient care. Just as burnout has been demonstrated to decrease the quality of healthcare, ${ }^{25-}$ ${ }^{27}$ the gradual erosion of ownership may play the same role.

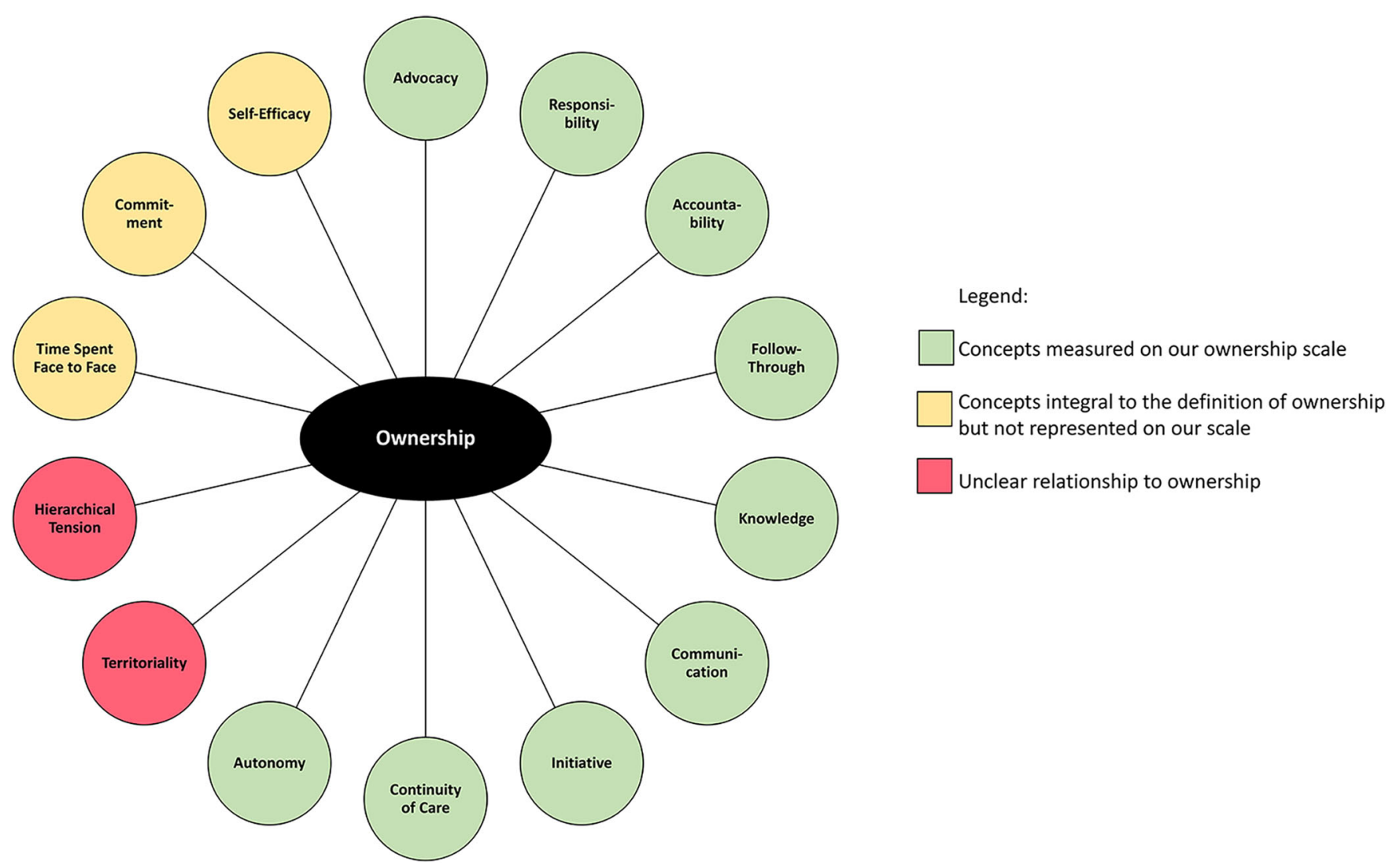

Figure 2 Working definition of ownership. This graphic illustrates which concepts—based on both prior research and our own study-are integral to defining the multidimensional concept of ownership. The concepts shown in green are represented in our ownership scale. The concepts in yellow are thought to be important to the definition of ownership but are not represented in our scale; items measuring these concepts were eliminated during the cognitive interviewing process because they either had low face validity or were at high risk of social desirability bias or ceiling effect. The concepts in red were previously thought to be relevant to the definition of ownership but were not thought to be as relevant to the definition of ownership according to the cognitive interviewing portion of our study. 
a)

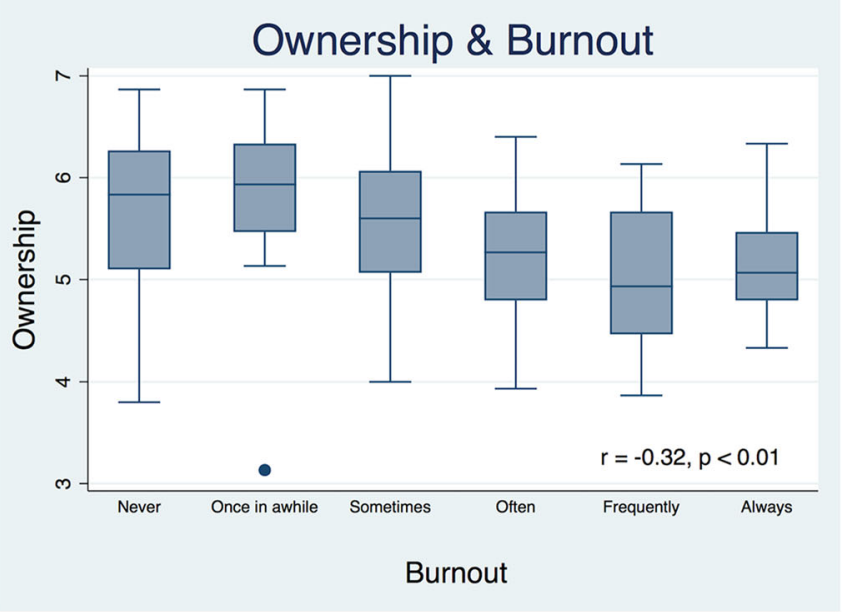

c)

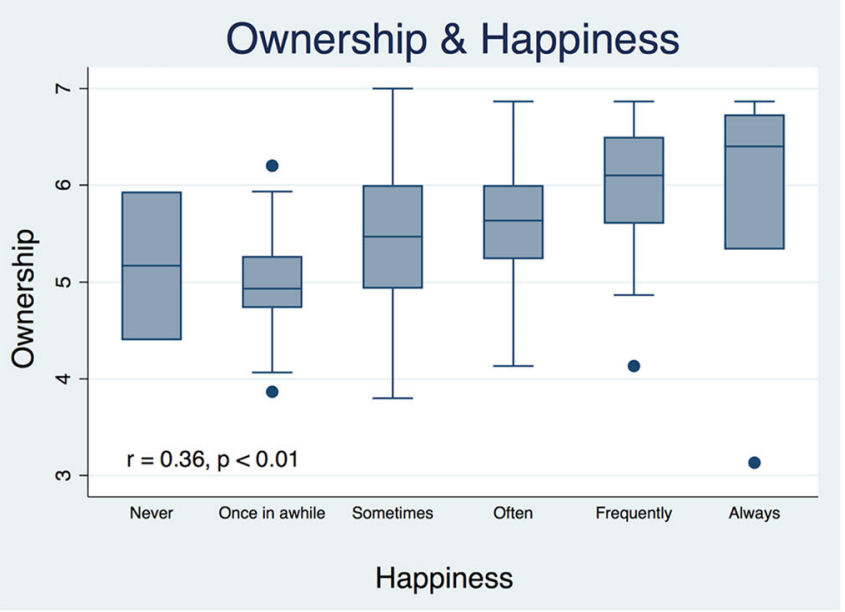

b)

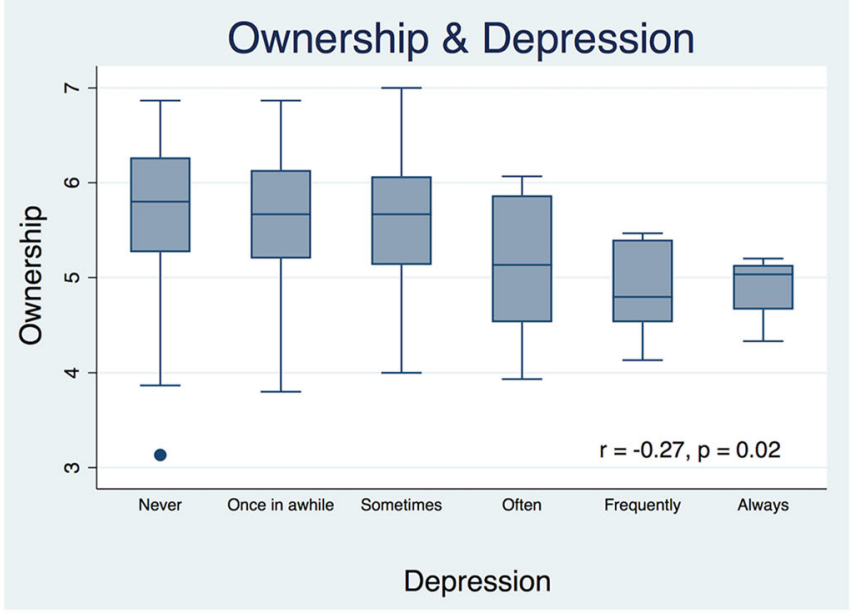

d)

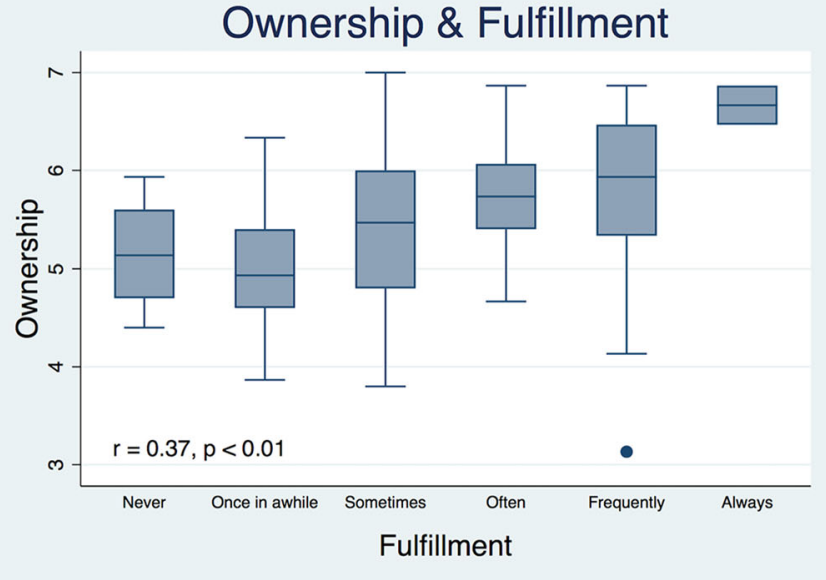

Figure 3 Relationship between ownership and burnout, depression, happiness, and fulfillment. Graphical depiction of the relationship between ownership and a burnout, b depression, $\mathrm{c}$ happiness, and $\mathbf{d}$ fulfillment. The $\boldsymbol{Y}$-axis represents mean ownership scores and the $X$-axis represents responses to the 6-point Likert scale measuring each affect ranging from $1=$ never to $6=$ always. For example, respondents were asked about their perceived degree of burnout as follows: Over the last month (or, 2 weeks), I felt burnt out. Each graph depicts the distribution of mean

Since our scale was adapted from existing research on ownership, we performed an exploratory factor analysis to identify latent constructs that may also define patient care ownership. The items loading on factor 1 all reflect decisional autonomy or assertiveness. Those loading on factor 2 corresponds to be the "go-to" person, and factor 3 to diligence. Prior research on patient care ownership did not identify assertiveness and diligence as essential concepts that contributed to its definition. A future confirmatory factor analysis will determine the stability of these subscales.

With future validation, we see several potential uses for our ownership scale. First, it may be used by medical educators to monitor ownership and to determine which changes to external factors (such as work environment or cultural norms) lead to an improved sense of ownership among trainees. Second, our scale might be useful for investigating how ownership influences care utilization and healthcare outcomes.

Our study has several limitations. Since this is the first objective measure of patient ownership among physicians, there is no gold standard for comparison. The cognitive interviewing portion of our study was subject to common issues in qualitative research such as experimenter bias and confirmation bias. Our study was also subject to common issues with survey data such as recall bias, inaccurate recall, social desirability bias, and ceiling effect. Another limitation is that self-efficacy, which is central to the definition of ownership, is not represented in our scale because those items were thought to be too high risk of bias. This means that our scale does not capture all the constructs that define ownership.

We did not use validated scales for some factors (such as burnout and depression) because existing burnout and depression scales have high correlations with perceived degree of burnout and depression, respectively, according to prior studies. ${ }^{28,}{ }^{29}$ We therefore included single items for these factors to minimize respondent burden.

While we intentionally limited our study population to one medical specialty at one institution to control for confounders, 
this may have prevented detection of true differences in ownership among different environmental factors. We will need to externally validate our scale in a larger population at different institutions. Another limitation is that some scale items only capture the experience of working as a trainee in an inpatient, team-based setting. We will need to revise the scale to make it applicable to the outpatient setting and to attending physicians in future studies (which will also require validation).

In conclusion, we developed an instrument to measure decision ownership of patient care. With further validation, our scale can be potentially used to research interventions aimed at fostering ownership and to investigate how ownership influences physician decision-making and behavior, care utilization, and patient outcomes.

Acknowledgments: The authors gratefully acknowledge Kevin Chen, MD, of the National Clinician Scholars Program at Yale University School of Medicine and the Veterans Affairs Connecticut Healthcare System for facilitating development of the figures.

Corresponding Author: Mia Djulbegovic, MD; National Clinician Scholars Program, Yale University School of Medicine, 333 Cedar Street, Courier SHM IE-66, PO Box 208088, New Haven, CT 06510, USA (e-mail: mia.djulbegovic@yale.edu).

Funders Research reported in this publication was financially supported by the Yale-New Haven Hospital Traditional Internal Medicine Residency's Research in Residency Program, the National Clinician Scholars Program at Yale University School of Medicine, and the Veterans Affairs Connecticut Healthcare System. This study was funded by the National Institute of Arthritis and Musculoskeletal and Skin Diseases, part of the National Institutes of Health, under Award Number AR060231-06 (Fraenkel).

\section{Compliance with Ethical Standards:}

Conflict of Interest: The authors declare that they do not have a conflict of interest.

Disclaimer: The funding sources had no role in the design or conduct of the study: collection, management, analysis, or interpretation of the data; preparation, review, or approval of the manuscript; or the decision to submit the manuscript for publication. The content is solely the responsibility of the authors and does not necessarily represent the official views or policies of Yale-New Have Health, Yale University, the National Clinician Scholars Program, the Veterans Affairs Healthcare System, the National Institutes of Health, nor the US Government.

Prior Presentations: This work was presented as an oral abstract at the Society of General Internal Medicine annual meeting in April of 2018 in Denver, $\mathrm{CO}$

\section{REFERENCES}

1. Dubov A, Fraenkel L, Seng E. The importance of fostering ownership during medical training. Am J Bioeth. 2016;16(9):3-12.

2. Pierce JL, Kostova T, Dirks KT. The State of Psychological Ownership: Integrating and Extending a Century of Research. Rev Gen Psychol. 2003;7(1):84-107. https://doi.org/10.1037//1089-2680.7.1.84

3. Pierce JL, Kostova T, Dirks KT. Toward a theory of psychological ownership in organizations. Acad Manag Rev. 2001;26(2):298-310.

4. Pierce JL, O'Driscoll MP, Coghlan A-M. Work environment structure and psychological ownership: The mediating effects of control. J Soc Psychol. 2004;144(5):507-34. https://doi.org/10.3200/SOCP.144.5. 507-534
5. Pierce JL, Jussila I. Collective psychological ownership within the work and organizational context: Construct introduction and elaboration. J Organ Behav. 2010;31(6):810-34. https://doi.org/10.1002/job.628

6. Avey JB, Avolio BJ, Crossley CD, Luthans F. Psychological ownership: Theoretical extensions, measurement and relation to work outcomes. J Organ Behav. 2009;30(2):173-91. https://doi.org/10.1002/job.583

7. Lee DY, Myers EA, Rehmani SS, et al. Surgical residents' perception of the 16-hour work day restriction: concern for negative impact on resident education and patient care. J Am Coll Surg. 2012;215(6):868-77.

8. Griner D, Menon RP, Kotwall CA, Clancy TV, Hope Ww. The eightyhour workweek: surgical attendings' perspectives. Journal of Surgical Education 2010;67(1):25-31.

9. Drolet BC, Whittle SB, Khokhar MT, Fischer SA, Pallant A. Approval and perceived impact of duty hour regulations: survey of pediatric program directors. Pediatrics. 2013;132(5):819-24.

10. Pincavage AT, Dahlstrom M, Prochaska M, et al. Results of an enhanced clinic handoff and resident education on resident patient ownership and patient safety. Acad Med. 2013;88(6):795-801.

11. Desai SV, Asch DA, Bellini LM, et al. Education outcomes in a duty-hour flexibility trial in internal medicine. N Engl J Med. 2018;378(16):1494508.

12. Avey JB, Avolio BJ.. Psychological Ownership Questionnaire. Psychological Ownership Questionnaire (POQ). Menlo Park, CA: Mind Garden.2009.

13. Vandewalle D. Psychological Ownership: An Empirical Examination of its Consequences. Group Org Manag. 1995;20(2):210-26. https://doi.org/ $10.1177 / 1059601195202008$

14. Olckers C. Psychological ownership: Development of an instrument. SAJ Ind Psychol. 2013;39(2 SPL). https://doi.org/10.4102/sajip.v39i2.1105

15. Kline P. Handbook of Psychological Testing: Abingdon: Routledge; 2013.

16. DeVellis RF. Scale development: Theory and Applications: Thousand Oaks: Sage publications; 2016.

17. McLaren K, Lord J, Murray SB, et al. Ownership of patient care: a behavioural definition and stepwise approach to diagnosing problems in trainees. Perspect Med Educ. 2013. https://doi.org/10.1007/s40037013-0058-Z

18. Cowley DS, Markman JD, Best JA, et al. Understanding ownership of patient care: A dual-site qualitative study of faculty and residents from medicine and psychiatry. Perspect Med Educ. 2017:1-8.

19. Kim H, Sefcik JS, Bradway C. Characteristics of qualitative descriptive studies: a systematic review. Res Nurs Health. 2017;40(1):23-42.

20. Beckstead JW. On measurements and their quality. Paper 4: Verbal anchors and the number of response options in rating scales. Int $\mathrm{J}$ Nurs Stud. 2014;51(5):807-14.

21. Brown G, Lawrence TB, Robinson SL. Territoriality in organizations. Acad Manag Rev. 2005;30(3):577-94.

22. Jager AJ, Tutty MA, Kao AC, editors. Association between physician burnout and identification with medicine as a calling. Mayo Clinic Proceedings; 2017: Elsevier.

23. Shanafelt TD, Dyrbye LN, West CP. Addressing physician burnout: The way forward. JAMA. 2017;317(9):901-2. https://doi.org/10.1001/jama. 2017.0076

24. Shanafelt TD, Dyrbye LN, Sinsky C, et al. Relationship Between Clerical Burden and Characteristics of the Electronic Environment With Physician Burnout and Professional Satisfaction. Mayo Clin Proc. 2016;91(7):836-48. https://doi.org/10.1016/j.mayocp.2016.05.007

25. Shanafelt TD, Balch CM, Bechamps G, et al. Burnout and medical errors among American surgeons. Ann Surg. 2010;251(6):995-1000.

26. Grol R, Mokkink H, Smits A, et al. Work satisfaction of general practitioners and the quality of patient care. Fam Pract. 1985;2(3):128-35.

27. Landon BE, Reschovsky JD, Pham HH, Blumenthal D. Leaving medicine: the consequences of physician dissatisfaction. Med Care. 2006;44(3):234-42.

28. Montiel-Company JM, Subirats-Roig C, Flores-Martí P, Bellot-Arcis C, Almerich-Silla JM. Validation of the Maslach Burnout Inventory-Human Services Survey for Estimating Burnout in Dental Students. J Dent Educ. 2016;80(11):1368.

29. Beck AT, Rial WY, Rickels K. Short Form of Depression Inventory: Cross-validation. Psychol Rep. 1974;34(3, Pt 2):1184-6.

Publisher's Note Springer Nature remains neutral with regard to jurisdictional claims in published maps and institutional affiliations. 